\title{
Postnatal glucocorticoid use impacts renal function in VLBW
}

\section{neonates}

\author{
Christiane Mhanna ${ }^{1}$, Merlin Pinto ${ }^{2}$, Hannah Koechley ${ }^{2}$, Naveen Kannekanti $^{2}$, Rupesh Raina ${ }^{3}$, Prabhu Parimi ${ }^{2}$ and Prem Shekhawat ${ }^{2}{ }^{\bowtie}$
}

(c) The Author(s), under exclusive licence to the International Pediatric Research Foundation, Inc 2021

BACKGROUND: Preterm neonates often require glucocorticoids to manage refractory hypotension, prevent, and treat bronchopulmonary dysplasia. We have investigated the effect of cumulative dose and duration of glucocorticoids on blood pressure and renal function in VLBW infants.

METHODS: In this retrospective cohort study, medical records of infants (GA $\leq 35$ weeks) born January 2015 to December 2019 were reviewed to extract demographic and clinical characteristics, dose and duration of steroids, blood pressure (BP), and creatinine at the time of discharge from the neonatal intensive care unit.

RESULTS: Two hundred and eighty-three neonates with average GA ( $28 \pm 3$ weeks) and birthweight (1060 $\pm 381 \mathrm{~g})$. Twenty-eight percent $(33 / 116)$ of infants who received postnatal steroids developed hypertension versus $16 \%(27 / 167)$ of controls $(\mathrm{OR}=2.0, p=0.011)$. There was a correlation between the cumulative dosage of postnatal steroids and systolic $\operatorname{BP}\left(R^{2}=0.06, p<0.001\right)$. With increasing steroid dose and total steroid days, there was a significant increase in creatinine clearance at the time of discharge $\left(R^{2}=0.13, p<0.001 ; R^{2}=0.13\right.$, $p<0.001$, respectively).

CONCLUSIONS: Cumulative dose of postnatal steroids and duration of use is associated with increased systolic BP in premature infants. Postnatal steroids should be used prudently to prevent long-term cardiovascular and renal morbidity.

Pediatric Research (2022) 91:1821-1826; https://doi.org/10.1038/s41390-021-01624-1

\section{IMPACT:}

- Preterm neonates are exposed to a high dose of glucocorticoids during their neonatal intensive care stay.

- The dose and duration of use of postnatal glucocorticoids was associated with significant increase in blood pressure at the time of discharge in preterm neonates.

- Postnatal glucocorticoid use is associated with improved creatinine clearance likely due to a state of hyperfiltration and may lead to chronic kidney disease later in life.

- Postnatal glucocorticoids should be used prudently in this highly vulnerable population

\section{BACKGROUND}

Preterm birth, defined as delivery before 37 weeks gestational age (GA), accounts for roughly $12 \%$ of total births in the US and is responsible for the majority of morbidity and mortality in newborns. With improvements in technology and advances in neonatal intensive care unit (NICU), premature infants, especially those between 22 and 26 weeks, are now surviving due to proactive and vigorous resuscitation efforts followed by neonatal intensive care. ${ }^{1}$ Low birth weight (birthweight $<2500 \mathrm{~g}$ ) infants, especially those who are small-for-gestational age, have 5-10-fold greater mortality in the perinatal periods compared to those who are appropriate for their gestational age. Long-term follow-up studies of this population have shown a relationship between prematurity and cardiovascular disease, respiratory illness, hypertension (HTN), and chronic kidney disease (CKD). ${ }^{2}$ These infants are frequently exposed to high doses of glucocorticoids for maintenance of blood pressure, weaning off mechanical ventilation, and for prevention and treatment of bronchopulmonary dysplasia (BPD).

BPD, a form of chronic lung disease that affects newborns who are born preterm, exposed to high concentration of oxygen and mechanical ventilation, develop HTN and CKD later in life in 5-40\% of cases. ${ }^{3-6}$ Although the definitive cause of the HTN in BPD cases is unclear, investigators have suspected.involvement of chronic hypoxemia, acute kidney injury, and compromised renal circulation. 3,6 Most infants diagnosed with BPD do not manifest HTN until around the time of discharge from the NICU. Preterm neonates, especially those born between 22 and 34 weeks GA, are born with a lower number of nephrons compared to term neonates, ${ }^{7}$ thus are highly vulnerable to kidney injury which may later lead to CKD. ${ }^{8-13}$

Glucocorticoids in physiological concentration range play a critical role in renal development during prenatal as well as postnatal periods, but exposure to excessive amounts of

${ }^{1}$ Department of Pediatrics, The Cleveland Clinic Children's Hospital, Cleveland, OH, USA. ${ }^{2}$ MetroHealth Medical Center, Department of Pediatrics, Division of Neonatology, Cleveland, OH, USA. ${ }^{3}$ Akron Children's Hospital, Department of Pediatric Nephrology, Akron, OH, USA. ${ }^{凶}$ email: pshekhawat@metrohealth.org 
glucocorticoids in utero have been shown to hamper renal development in animal and human studies. ${ }^{14-16}$ Long-acting fluorinated steroids like betamethasone and dexamethasone have been shown to lead to elevated blood pressure and renal programming which is associated with HTN later in life. ${ }^{17,18}$ Sick, extremely low birth weight, preterm neonates, especially those with intrauterine growth restriction (IUGR) and small-for-gestational age (SGA), are exposed to multiple courses of stress doses of steroids (4-5 mg/kg/day hydrocortisone equivalent dose) over the course of their NICU stay. The impact of such exposure on renal function at the time of hospital discharge has not been clearly elucidated.

The American Academy of Pediatrics (AAP) does not recommend routine screening for HTN in children until after the age of 3 years unless comorbid conditions are present. ${ }^{19}$ The clinical presentation of HTN in premature infants after discharge is nonspecific with symptoms like poor feeding, tachypnea, irritability, and lethargy. Such subtle signs could easily be missed by primary care physicians. ${ }^{20}$ Thus, we hypothesized that HTN in these very low birth weight (VLBW) convalescent neonates is not only related to BPD but also to the dose and duration of exposure to postnatal steroids as postnatal steroid use impacts renal function at the time of discharge home.

\section{METHODS \\ Study design}

We conducted a retrospective cohort chart review of patients from MetroHealth Medical Center, affiliated with Case Western Reserve University, Cleveland, Ohio between January 2015 and January 2019.

\section{Inclusion criteria}

All premature infants born with gestational age $\leq 35$ weeks and birthweight $\leq 1500 \mathrm{~g}$ that were admitted to the NICU.

\section{Exclusion criteria}

Infants with known congenital malformations, birth asphyxia as defined by standard hypoxic-ischemic encephalopathy criteria, and infants transferred from an outside hospital were excluded.

\section{Study protocol}

Blood pressure was obtained using a standard oscillometry method (Philips noninvasive blood pressure monitor) with an appropriately sized cuff when the infant was undisturbed, sleeping, or in a quiet wakefulness state. Three consecutive systolic, diastolic, and mean blood pressure (BP) measurements recorded in the medical records at the time of discharge home were extracted. Pulse pressure (PP) and mean arterial pressures (MAP), which represents the pulsatile component of blood pressure curve and MAP and is a steady component related to perfusion, were calculated using the following formula:

pulse pressure $(\mathrm{PP})=\mathrm{SBP}-\mathrm{DBP}$

mean arterial pressure $(\mathrm{MAP})=(\mathrm{SBP}+2 \times \mathrm{DBP}) / 3$

Medical records were reviewed for infant demographic, clinical characteristics, type, dosage and duration of postnatal steroids, and creatinine at the time of discharge. Collected demographic and clinical data included gestational age, birthweight, head circumference, sex, race, APGAR scores, length of NICU stay, antenatal betamethasone use, surfactant use, ventilator days, patent ductus arteriosus diagnosis and management (medical versus surgical), total postnatal steroid days, and total steroid dose exposure. Maternal information extracted included type of delivery, chorioamnionitis, maternal pre-eclampsia, and eclampsia. Additional information obtained at the time of discharge included diagnosis of SGA (small-for-gestational age), IUGR, diagnosis of BPD as defined by the National Institute of Health consensus statement of $2001,{ }^{21}$ culture proven bacterial sepsis, weight, length, blood urea nitrogen, and serum creatinine. BPD was defined as $\mathrm{FiO}_{2}>21 \%$ for at least 28 days with severity classified as mild $\left(\mathrm{FiO}_{2}=21 \%\right)$, moderate $\left(\mathrm{FiO}_{2}<30 \%\right)$, or severe $\left(\mathrm{FiO}_{2}\right.$ at least $30 \%$ and/or positive pressure support). ${ }^{21}$
Postnatal glucocorticoids prescribed included mostly hydrocortisone, and rarely dexamethasone and prednisolone. All steroids used were converted to the hydrocortisone equivalent dose using the following ratio of potency: dexamethasone 1:40, betamethasone 1:40, prednisolone 1:5, hydrocortisone 1:1. ${ }^{22}$ HTN in our study was defined as mean BP $>95$ th percentile and severe HTN as mean BP >99th percentile for corrected gestational age at the time of discharge. ${ }^{23}$

Serum creatinine was obtained via the Jaffe method, which is a colorimetric method to assay blood or urine. Creatinine clearance $(\mathrm{CrCl})$ at the time of NICU discharge was calculated using the Schwartz formula equation: ${ }^{24}$

$\mathrm{CrCl} \mathrm{ml} / \mathrm{min} / 1.73 \mathrm{~m}^{2}=k \times$ height $(\mathrm{cm}) /$ creatinine $(\mathrm{mg} / \mathrm{dl})$,

where $k=0.45$, the constant for infants less than 1 year of age.

\section{Ethical issues}

The study was approved by the Institutional Review Board at MetroHealth Medical Center.

\section{Statistical analysis}

Data were entered into the REDCap ${ }^{\circ}$ database, a browser-based metadatadriven software and workflow methodology for clinical and translational research, and later exported to Microsoft Excel and SPSS v24 for analysis. Demographic data of study population were analyzed and presented as descriptive statistics, the mean and standard deviations were calculated, and categorical data were presented as percentages. The comparison between groups was performed using $t$-test for parametric data and Mann-Whitney $U$ test for non-parametric data. Chi-square test and Fisher exact tests were used for categorical data as appropriate. Odds ratio and $95 \%$ confidence intervals were calculated. A correlation analysis was conducted between SBP, DBP, PP, cumulative dose and duration of steroids, serum creatinine, and creatinine clearance. To adjust for GA, logistic regression analyses were conducted with blood pressures as the dependent variable and corrected GA at the time of discharge along with days of steroids or cumulative dose of steroids as independent variables. Additionally, logistic regression analyses were conducted with serum creatinine levels at discharge as the dependent variable and corrected GA at the time of discharge along with days of steroids or cumulative dose of steroids as independent variables. Data analysis was conducted using SPSS version 24 .

\section{RESULTS}

The Neonatal Intensive Care Unit at MetroHealth Medical Center is a Level $\mathrm{III}_{\mathrm{C}}$ inner-city high-risk tertiary care delivery center. There were 12,453 deliveries during the study period, of which 1758 infants were admitted to the NICU. A total of 283 infants met our inclusion criteria (154 males, 129 females), of whom 116 infants were steroid exposed and served as subjects and 167 nonexposed infants served as controls (Fig. 1 and Table 1). The mean

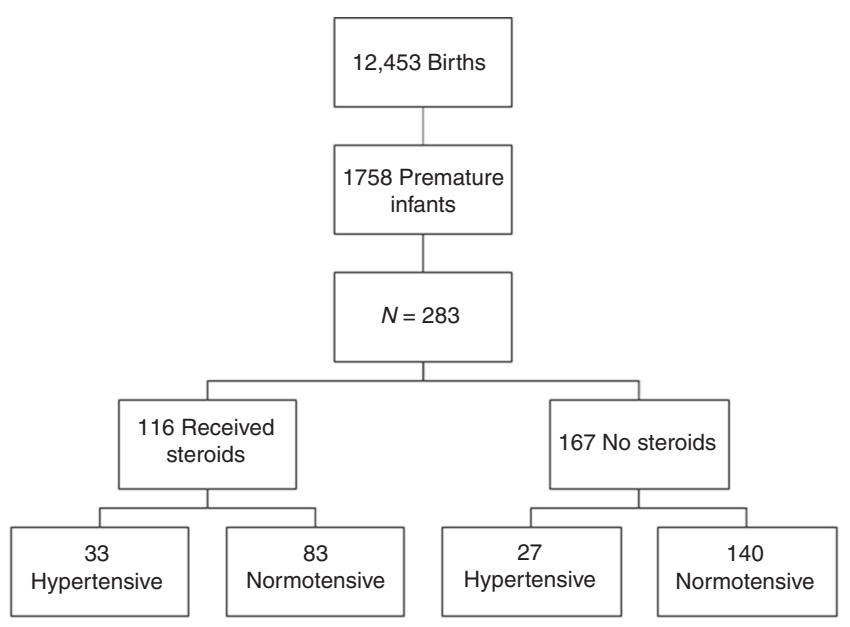

Fig. 1 Flow diagram of patient population. 
Table 1. Patient demographics and clinical characteristics.

\begin{tabular}{|c|c|c|c|}
\hline & $\begin{array}{l}\text { Steroid non- } \\
\text { exposed } \\
(n=167)\end{array}$ & $\begin{array}{l}\text { Steroid } \\
\text { exposed } \\
(n=116)\end{array}$ & $P$ value \\
\hline Birth weight (grams) & $\begin{array}{l}1222 \pm 275 \\
(530-1680)\end{array}$ & $\begin{array}{l}788 \pm 249 \\
(420-1460)\end{array}$ & $<0.001$ \\
\hline Gestational age (weeks) & $\begin{array}{l}29 \pm 2 \\
(24-35)\end{array}$ & $\begin{array}{l}25 \pm 2 \\
(22-33)\end{array}$ & $<0.001$ \\
\hline $\begin{array}{l}\text { Small-for-gestational } \\
\text { age (\%) }\end{array}$ & $12 \%(20 / 167)$ & $11 \%(13 / 116)$ & 0.843 \\
\hline Gender (\% male) & $56 \%(93 / 167)$ & $53 \%(61 / 116)$ & 0.629 \\
\hline African American (\%) & $\begin{array}{l}60 \%(101 / \\
167)\end{array}$ & $75 \%(87 / 116)$ & 0.01 \\
\hline Caucasian (\%) & $33 \%(55 / 167)$ & $20 \%(23 / 116)$ & 0.01 \\
\hline Asian (\%) & $4 \%(6 / 167)$ & $3 \%(4 / 116)$ & 0.948 \\
\hline Other (\%) & $3 \%(5 / 167)$ & $2 \%(2 / 116)$ & 0.498 \\
\hline $\begin{array}{l}\text { Antenatal } \\
\text { betamethasone (\%) }\end{array}$ & $\begin{array}{l}92 \%(153 / \\
167)\end{array}$ & $82 \%(95 / 116)$ & $<0.001$ \\
\hline Surfactant (\%) & $48 \%(80 / 167)$ & $\begin{array}{l}97 \%(112 / \\
116)\end{array}$ & $<0.001$ \\
\hline Delivery (\% C-section) & $\begin{array}{l}65 \%(109 / \\
167)\end{array}$ & $66 \%(76 / 116)$ & 0.966 \\
\hline Maternal diabetes & $13 \%(21 / 167)$ & $9 \%(10 / 116)$ & 0.589 \\
\hline Gestational & $7 \%(12 / 167)$ & $2 \%(2 / 116)$ & \\
\hline Type I & $1 \%(2 / 167)$ & $3 \%(3 / 116)$ & \\
\hline Type II & $4 \%(7 / 167)$ & $4 \%(5 / 116)$ & \\
\hline Maternal pre-eclampsia & $36 \%(60 / 167)$ & $25 \%(29 / 116)$ & 0.04 \\
\hline Maternal eclampsia & $0.6 \%(1 / 167)$ & $0 \%(0 / 167)$ & 0.319 \\
\hline $\begin{array}{l}\text { Maternal } \\
\text { chorioamnionitis }\end{array}$ & $29 \%(48 / 167)$ & $39 \%(45 / 116)$ & 0.094 \\
\hline Treated PDA (\%) & $6 \%(10 / 167)$ & $33 \%(38 / 116)$ & $<0.001$ \\
\hline Ibuprofen & $5 \%(9 / 167)$ & $18 \%(21 / 116)$ & \\
\hline Surgical & $0.6 \%(1 / 167)$ & $15 \%(17 / 116)$ & \\
\hline Sepsis (culture positive) & $8 \%(14 / 167)$ & $28 \%(33 / 116)$ & $<0.001$ \\
\hline Apgar at $1 \mathrm{~min}$ & $7(1-9)$ & $4(1-9)$ & $<0.001$ \\
\hline Apgar at $5 \mathrm{~min}$ & $8(2-9)$ & $6(1-9)$ & $<0.001$ \\
\hline Days of ventilation & $30(0-185)$ & $108(0-353)$ & $<0.001$ \\
\hline Nitric oxide use & $0.6 \%(1 / 167)$ & $4 \%(5 / 116)$ & 0.064 \\
\hline $\begin{array}{l}\text { Bronchopulmonary } \\
\text { dysplasia (\%) }\end{array}$ & $33 \%(55 / 167)$ & $84 \%(97 / 116)$ & $<0.001$ \\
\hline Mild BPD & $26 \%(44 / 167)$ & $31 \%(36 / 116)$ & \\
\hline Moderate BPD & $5 \%(9 / 167)$ & $36 \%(42 / 116)$ & \\
\hline Severe BPD & $1 \%(2 / 167)$ & $16 \%(19 / 116)$ & \\
\hline Length of stay (days) & $\begin{array}{l}56 \pm 26 \\
(17-185)\end{array}$ & $\begin{array}{l}121 \pm 54 \\
(36-353)\end{array}$ & $<0.001$ \\
\hline $\begin{array}{l}\text { Corrected gestational } \\
\text { age at discharge (weeks) }\end{array}$ & $38 \pm 3$ & $43 \pm 7$ & $<0.001$ \\
\hline
\end{tabular}

birthweight of our cohort was $1060 \pm 381 \mathrm{~g}$ and gestational age $28 \pm 3$ weeks. Hydrocortisone was prescribed for majority of our patient population with few exceptions. Dexamethasone was prescribed as a low-dose short (3 days) course therapy mainly for cases with upper airway edema or to facilitate extubation. Prednisolone was rarely used, mainly in convalescent severe BPD cases. All 116 infants received hydrocortisone, of which 30 infants received a combination of dexamethasone and hydrocortisone with dexamethasone being prescribed for a short period of time and only two infants received prednisolone 1-2 weeks prior to discharge home.
Patient clinical characteristics and demographics are summarized in Table 1. There were statistically significant differences between steroid exposed and non-exposed subjects in terms of steroid use, birthweight, GA, race, antenatal betamethasone exposure, surfactant use, maternal pre-eclampsia, treated PDA, culture proven sepsis, APGARs at 1 and $5 \mathrm{~min}$ of life, days of mechanical ventilation, BPD, and length of NICU stay (Table 1). Among all infants, 21\% (60/283) developed HTN and 10\% (27/283) developed severe HTN at the time of discharge from the NICU (Table 2).

Among infants who received postnatal steroids (exposed group), 28\% (33/116) developed HTN versus $16 \%$ (27/167) of non-exposed group (OR $[\mathrm{Cl}]=2.0[1.2-3.7], p=0.01$ ) (Table 2). Similarly, among patients who were exposed to postnatal steroids, $15 \%(17 / 116)$ developed severe HTN versus $6 \%(10 / 167)$ of nonexposed infants (OR $[\mathrm{Cl}]=2.7[1.2-6.1], p=0.02)$. There was no statistically significant difference between patients who were exposed or not exposed to steroids regarding their diastolic or mean arterial BP.

In the logistic regression analysis with SBP as the dependent variable and total days of steroids and corrected GA at discharge as the independent variables, there was a statistically significant correlation between the number of days of steroids and corrected GA at discharge and SBP. Similarly, with SBP $>95 \%$ as the dependent variable and total cumulative dose of steroids and corrected GA at discharge as the independent variable, there was a statistically significant correlation between the total cumulative dose of steroid exposure and corrected GA at the time of discharge and SBP ( $p=0.03$ and 0.02 respectively) (Table 3 ). We found a significant correlation between total days exposure to steroids and SBP (Fig. 2a: $R^{2}=0.0704, p<0.0001$ ) as well as a correlation between cumulative dose of postnatal steroid exposure and SBP (Fig. $2 \mathrm{~b}: R^{2}=0.059, p<0.001$ ). Furthermore, there was a significant association between total steroid days and PP (Fig. 2c: $R^{2}=0.03, p=0.008$ ) as well as cumulative dose of postnatal steroids and PP (Fig. $2 \mathrm{~d}: R^{2}=0.024, p=0.02$ ).

Overall, diagnostic testing at discharge was notable for mean creatinine of $0.46 \pm 0.17 \mathrm{mg} / \mathrm{dl}$ in all VLBW infants, $0.27 \pm 0.10 \mathrm{mg} / \mathrm{dl}$ in those that were exposed to postnatal steroids, and $0.47 \pm 0.45 \mathrm{mg} / \mathrm{dl}$ in non-exposed $(p<0.001)$. Mean $\mathrm{CrCl}$ in all VLBW infants was $50 \pm 19$ $\mathrm{ml} / \mathrm{min}$, with $92 \pm 32 \mathrm{ml} / \mathrm{min}$ in those who were exposed to postnatal steroids and $69 \pm 2 \mathrm{ml} / \mathrm{min}$ in non-exposed $(p<0.001)$.

There was a statistically significant decrease in creatinine with increased steroid days (Fig. 3a: $R^{2}=0.10, p<0.001$ ) and total cumulative steroid dose (Fig. $3 \mathrm{~b}: R^{2}=0.08, p<0.001$ ). With increasing cumulative steroid dose and total steroid exposure days, there was a statistically significant increase in creatinine clearance at time of discharge (Fig. 3c, d: $R^{2}=0.13, p<0.001 ; R^{2}=$ $0.13, p<0.001$, respectively). In the logistic regression analysis with $\mathrm{CrCl}$ as the dependent variable and total days of steroids and corrected GA at discharge as the independent variable, there was a statistically significant correlation between the number of days of steroid exposure and corrected gestational age at discharge and $\mathrm{CrCl}$ (Table 4). When $\mathrm{CrCl}$ was the dependent variable and total dose of steroids and corrected GA at discharge were the independent variable, we did not find any statistically significant difference (Table 4) $(p=0.13)$.

\section{DISCUSSION}

Our retrospective cohort study is the first to report that total cumulative dose and duration of postnatal glucocorticoid exposure in the NICU are associated with HTN at the time of discharge in VLBW neonates. Postnatal steroid exposure was also significantly associated with improved $\mathrm{CrCl}$ at the time of discharge. This association of postnatal steroids and HTN was suspected in the past but never analyzed as we have done in our work. High-dose steroids increase distal sodium transport and 
Table 2. Incidence of hypertension.

\begin{tabular}{|c|c|c|c|c|}
\hline & Steroid exposed $(N=116)$ & Steroid non-exposed $(N=167)$ & Odds ratio $[95 \% \mathrm{Cl}]$ & $P$ value \\
\hline HTN (SBP > 95\%ile) & $33 / 116(28 \%)$ & $27 / 167$ (16\%) & $2.0[1.2-3.7]$ & $0.01^{*}$ \\
\hline Severe HTN (SBP > 99\%ile) & $17 / 116(15 \%)$ & $10 / 167(6 \%)$ & $2.7[1.2-6.1]$ & $0.02 *$ \\
\hline HTN (DBP > 95\%ile) & $5 / 116(4 \%)$ & $4 / 167(2 \%)$ & $1.8[0.5-6.9]$ & 0.37 \\
\hline Severe HTN (DBP > 99\%ile) & $1 / 116(0.9 \%)$ & $2 / 167(1.2 \%)$ & $0.7[0.1-8.0]$ & 0.79 \\
\hline HTN (MAP > 95\%ile) & $7 / 116(6 \%)$ & $4 / 167(2 \%)$ & $2.6[0.8-9.2]$ & 0.16 \\
\hline Severe HTN (MAP > 99\%ile) & $2 / 116(2 \%)$ & $2 / 167(1 \%)$ & $1.5[0.2-10.4]$ & 0.74 \\
\hline
\end{tabular}

HTN hypertension, SBP systolic BP, DBP diastolic BP, MAP mean arterial BP.

* significant $P$ value.

Table 3. Risk factors associated with systolic blood pressure $>95$ percentile corrected for gestation age at discharge.

\begin{tabular}{|llll|} 
& Adjusted odds ratio & 95\% Cl & \\
\hline Total days on steroids & 1.014 & $1.0061-1.028$ & value \\
\hline Total dose of steroids & 1.006 & $1.001-1.011$ & 0.032 \\
\hline
\end{tabular}
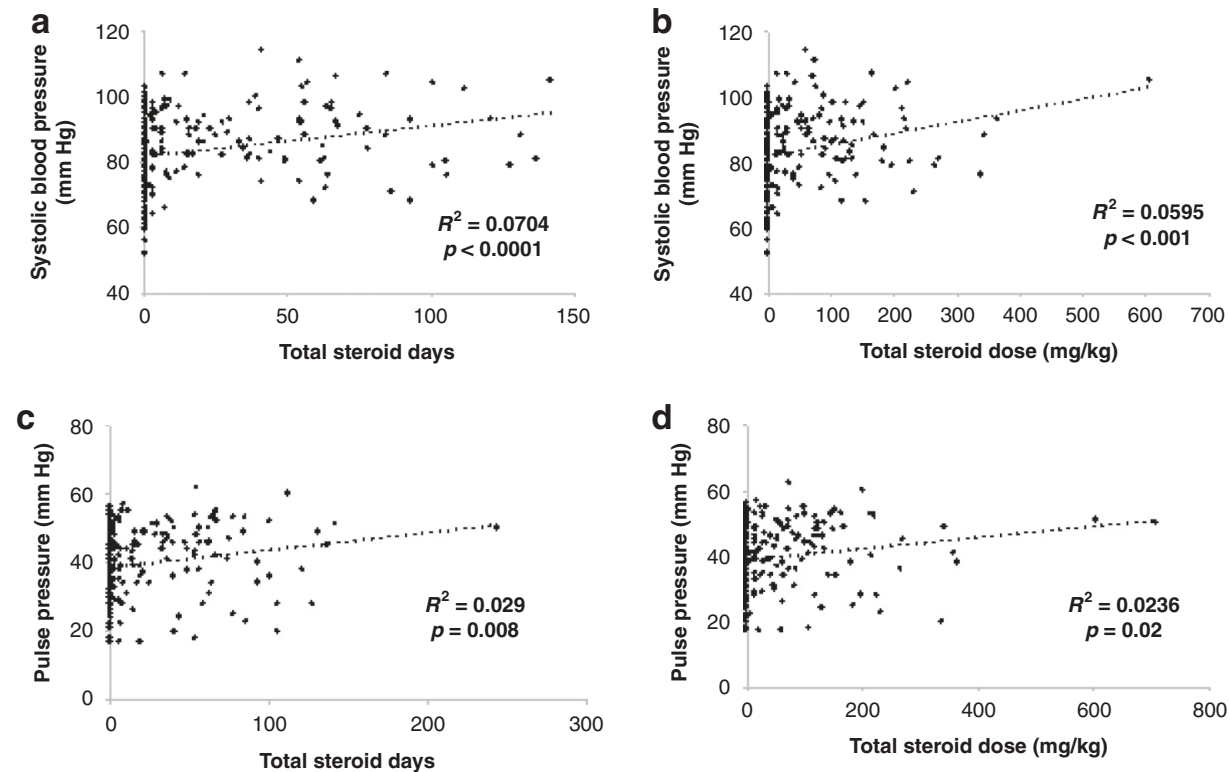

Fig. 2 Relationship between systolic blood pressure and pulse pressure to total hydrocortisone equivalent dose and duration of exposure. a Relationship between systolic blood pressure and total days on steroids; $\mathbf{b}$ relationship between systolic blood pressure and total dose of steroids; c relationship between pulse pressure and total days on steroids; $\mathbf{d}$ relationship between pulse pressure and total steroid dose.

increase intravascular volume which indirectly increases glomerular filtration leading to a state of hyperfiltration and clinically improved laboratory values. Steroids acting through their genomic effects on steroid response element (SRE) in various genes have been shown to up- or down-regulates several genes related to serum and glucocorticoid kinase 1 (SGK-1) tight junction proteins (Claudin-4, Claudin-8, Claudin-2, Zonulin-1), ion channels (ENaC, ROMK/BK, TRPV4/5/6, TRPM 7/6) which may also impact renal function in a yet to be defined fashion. ${ }^{25,26}$

The importance of our work is the fact that postnatal use of glucocorticoids is currently not standardized so these powerful medications are prescribed widely with no clear indication or defined start or end point for their use, resulting in their inappropriate use clinically. To illustrate our point, one infant in our cohort was exposed to a total of $710 \mathrm{mg} / \mathrm{kg}$ of hydrocortisone equivalent dose over a 244-day period whereas a clinically effective dose of hydrocortisone is roughly $1-2 \mathrm{mg} / \mathrm{kg} /$ day over a 3-4-day period. This same infant had the highest serum creatinine as well as lower $\mathrm{CrCl}$ (Figs. 2 and 3). We have adjusted our data for corrected gestational age at the time of discharge since the BP and creatinine levels were obtained at discharge and we still found a significant correlation between steroid use and HTN.

HTN was defined as blood pressure $>95$ th percentile for age and severe HTN is defined as blood pressure $>99$ th percentile for age. These values were based on the available reference tables for infants between 26 to 44 weeks postconceptional age. ${ }^{23}$ In healthy term infants, the incidence of HTN is $0.2 \%{ }^{20}$ and in neonates admitted to the NICU (all gestational ages), the incidence of HTN has been reported to range from 0.7 to $3 \%{ }^{27-29}$ In our cohort of VLBW infants, the incidence of HTN was 28 and $15 \%$ for severe HTN in the postnatal 

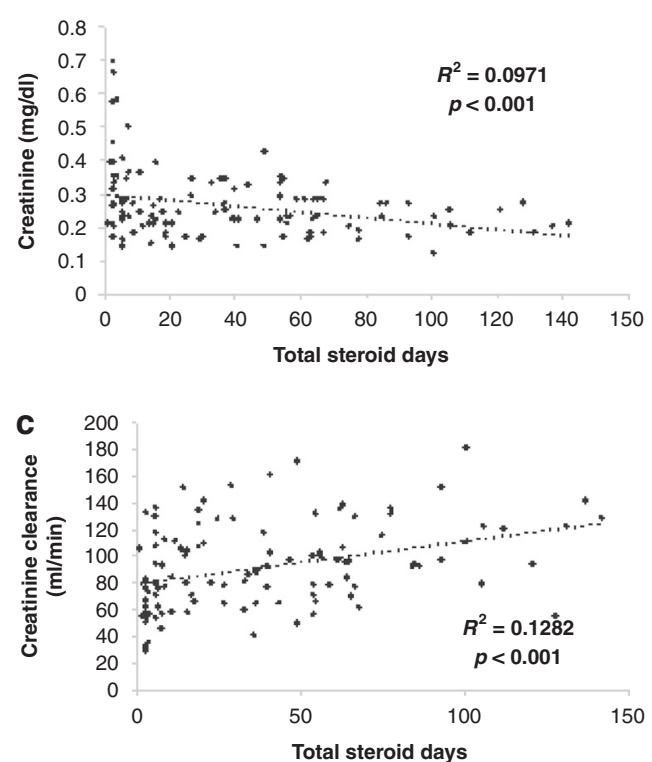

b
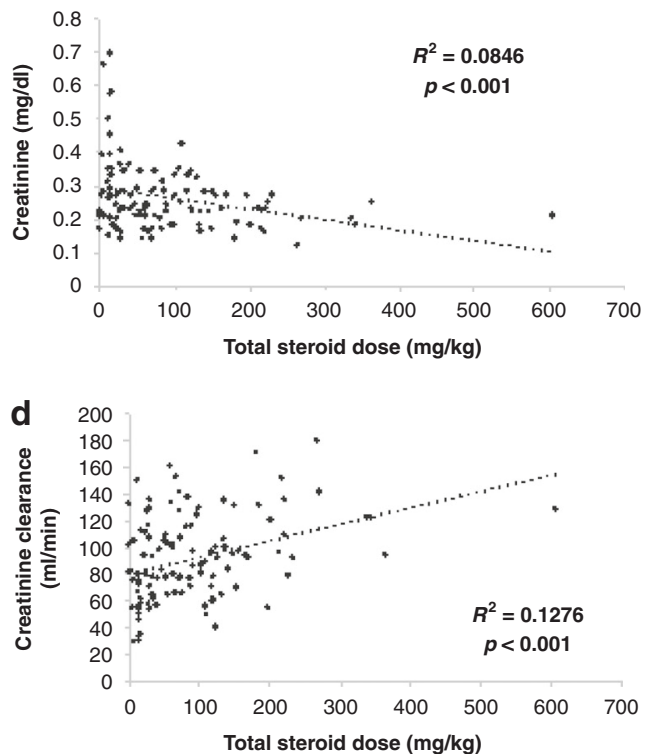

Fig. 3 Relationship of creatinine and creatinine clearance to total dose and duration of steroid exposure. a Relationship between creatinine and total days on steroids; $\mathbf{b}$ relationship between creatinine and total dose of steroids; $\mathbf{c}$ relationship between creatinine clearance and total days on steroids; $\mathbf{d}$ relationship between creatinine clearance and total steroid dose.

Table 4. Adjusted odds ratios for effect of total days of steroid use and cumulative dose of steroids on creatinine clearance corrected for gestational age at time of discharge.

\begin{tabular}{|llcl} 
& Adjusted odds ratio & 95\% Cl & \\
Total days on steroids & 0.170 & $0.014-0.344$ & \\
\hline Total dose of steroids & 0.120 & -0.015 to 0.112 & 0.034
\end{tabular}

steroid exposed group which underlines the extent of the problem. As for treatment of HTN, we first confirmed presence of HTN by at least three blood pressure measurements while infant was sleeping or in a state of quite wakefulness. Once confirmed a Pediatric Nephrology consult was obtained and our usual line of treatment is to stop use of postnatal steroids and use hydralazine for systolic blood pressure $>95 \%$ ile for GA as first line of treatment, followed by ACE inhibitors based on degree of HTN. Thus, it is critical to have outpatient follow-up of these infants to manage their HTN since there are long-term consequences of persistent HTN.

Our study has demonstrated that the creatinine clearance and estimated GFR increased in infants exposed to postnatal steroids because of hyperfiltration leads to short-term improvement in kidney function ${ }^{30-33}$ even though there was a concern for CKD development later in life. This effect hides the major concern for renal damage which may be occurring in these vulnerable infants and shows up clinically only later in life. Exposure to high-dose glucocorticoids in utero or ex utero till infants corrected to term gestational age have shown to cause several deleterious effects in human $^{34,35}$ as well as animal studies. ${ }^{16,36}$ Animal studies where experimental conditions were controlled have demonstrated formation of renal cysts, loss of nephrons, and dysmorphogenesis in kidneys after exposure to high-dose steroids besides fetal programming leading to HTN later in life. ${ }^{16,37-39}$

Results of our retrospective study have several limitations because of the smaller number of subjects, our ability to find similar control subjects, and our lack of ability to control for all confounding variables, thus multivariate analysis to control for all confounding variables could not be done. A similar study in a larger multi-center population may provide definitive answers but nevertheless, we have demonstrated a statistically significant association between the dose and duration of postnatal steroids to HTN at the time of discharge in VLBW infants. This finding assumes special importance clinically since postnatal steroids are widely prescribed with little or no regard for their impact on renal development and function. Thus, in summary, postnatal steroids should be used judiciously to prevent not only HTN but potentially CKD in these highly vulnerable infants.

\section{REFERENCES}

1. Allen, M. C., Cristofalo, E. A. \& Kim, C. Outcomes of preterm infants: morbidity replaces mortality. Clin. Perinatol. 38, 441-454 (2011).

2. Crump, C., Sundquist, K., Sundquist, J. \& Winkleby, M. A. Gestational age at birth and mortality in young adulthood. JAMA 306, 1233-1240 (2011).

3. Jenkins, R. D., Aziz, J. K., Gievers, L. L., Mooers, H. M., Fino, N. \& Rozansky, D. J. et al. Characteristics of hypertension in premature infants with and without chronic lung disease: a long-term multi-center study. Pediatr. Nephrol. 32, 2115-2124 (2017).

4. Abman, S. H., Warady, B. A., Lum, G. M. \& Koops, B. L. Systemic hypertension in infants with bronchopulmonary dysplasia. J. Pediatr. 104, 928-931 (1984).

5. Anderson, A. H., Warady, B. A., Daily, D. K., Johnson, J. A. \& Thomas, M. K. Systemic hypertension in infants with severe bronchopulmonary dysplasia: associated clinical factors. Am. J. Perinatol. 10, 190-193 (1993).

6. Alagappan, A. \& Malloy, M. H. Systemic hypertension in very low-birth weight infants with bronchopulmonary dysplasia: incidence and risk factors. Am. J. Perinatol. 15, 3-8 (1998).

7. Abitbol, C. L. \& Rodriguez, M. M. The long-term renal and cardiovascular consequences of prematurity. Nat. Rev. Nephrol. 8, 265-74-74 (2012).

8. Abitbol, C. L., Bauer, C. R., Montané, B., Chandar, J., Duara, S. \& Zilleruelo, G. Longterm follow-up of extremely low birth weight infants with neonatal renal failure. Pediatr. Nephrol. 18, 887-893 (2003). 
9. Fanos, V., Gerosa, C., Loddo, C. \& Faa, G. State of the art on kidney development: how nephron endowment at birth can shape our susceptibility to renal dysfunction later in life. Am. J. Perinatol. 36, S33-S36 (2019).

10. Baum, M. Role of the kidney in the prenatal and early postnatal programming of hypertension. Am. J. Physiol. Ren. Physiol. 298, F235-247 (2010).

11. Mackenzie, H. S., Lawler, E. V. \& Brenner, B. M. Congenital oligonephropathy: the fetal flaw in essential hypertension? Kidney Int. Suppl. 55, S30-S34 (1996).

12. Keller, G., Zimmer, G., Mall, G., Ritz, E. \& Amann, K. Nephron number in patients with primary hypertension. N. Engl. J. Med. 348, 101-108 (2003).

13. Shankaran, S., Das, A., Bauer, C. R., Bada, H., Lester, B. \& Wright, L. et al. Fetal origin of childhood disease: intrauterine growth restriction in term infants and risk for hypertension at 6 years of age. Arch. Pediatr. Adolesc. Med. 160, 977-981 (2006).

14. Ortiz, L. A., Quan, A., Weinberg, A. \& Baum, M. Effect of prenatal dexamethasone on rat renal development. Kidney Int. 59, 1663-1669 (2001).

15. Dickinson, H., Walker, D. W., Wintour, E. M. \& Moritz, K. Maternal dexamethasone treatment at midgestation reduces nephron number and alters renal gene expression in the fetal spiny mouse. Am. J. Physiol. Regul. Integr. Comp. Physiol. 292, R453-R461 (2007).

16. Chan, S. K., Riley, P. R., Price, K. L., McElduff, F., Winyard, P. J. \& Welham, S. J. et al. Corticosteroid-induced kidney dysmorphogenesis is associated with deregulated expression of known cystogenic molecules, as well as Indian hedgehog. Am. J. Physiol. Ren. Physiol. 298, F346-356 (2010).

17. Greenough, A., Emery, E. F. \& Gamsu, H. R. Dexamethasone and hypertension in preterm infants. Eur. J. Pediatr. 151, 134-135 (1992).

18. Smets, K. \& Vanhaesebrouck, P. Dexamethasone associated systemic hypertension in low birth weight babies with chronic lung disease. Eur. J. Pediatr. 155, 573-575 (1996).

19. Flynn, JT et al. Clinical practice guideline for screening and management of high blood pressure in children and adolescents. Pediatrics 140, e20171904 (2017).

20. American Academy of Pediatrics Committee on Fetus and Newborn: routine evaluation of blood pressure, hematocrit, and glucose in newborns. Pediatrics 92, 474-476 (1993).

21. Jobe, A. H. \& Bancalari, E. Bronchopulmonary dysplasia. Am. J. Respir. Crit. Care Med. 163, 1723-1729 (2001).

22. Miller, W. L. \& Fluck, C. E. Pediatric Endocrinology (Elsevier Saunders, 2014).

23. Dionne, J. M., Abitbol, C. L. \& Flynn, J. T. Hypertension in infancy: diagnosis, management and outcome. Pediatr. Nephrol. 27, 17-32 (2012).

24. Schwartz, G. J., Haycock, G. B., Edelmann, C. M. Jr. \& Spitzer, A. A simple estimate of glomerular filtration rate in children derived from body length and plasma creatinine. Pediatrics 58, 259-263 (1976).

25. Valinsky, W. C., Touyz, R. M. \& Shrier, A. Aldosterone, SGK1, and ion channels in the kidney. Clin. Sci. (Lond.) 132, 173-183 (2018).

26. Molina-Jijón, E., Rodríguez-Muñoz, R., González-Ramírez, R., Namorado-Tónix, C., Pedraza-Chaverri, J. \& Reyes, J. L. Aldosterone signaling regulates the overexpression of claudin-4 and -8 at the distal nephron from type 1 diabetic rats. PLOS ONE 12, e0177362 (2017).

27. Seliem, W. A., Falk, M. C., Shadbolt, B. \& Kent, A. L. Antenatal and postnatal risk factors for neonatal hypertension and infant follow-up. Pediatr. Nephrol. 22, 2081-2087 (2007).

28. Blowey, D. L., Duda, P. J., Stokes, P. \& Hall, M. Incidence and treatment of hypertension in the neonatal intensive care unit. J. Am. Soc. Hypertens. 5, 478-483 (2011).

29. Kraut, E. J., Boohaker, L. J., Askenazi, D. J., Fletcher, J. \& Kent, A. L. Incidence of neonatal hypertension from a large multicenter study [Assessment of Worldwide Acute Kidney Injury Epidemiology in Neonates-AWAKEN]. Pediatr. Res. 84, 279-289 (2018).

30. Stow, L. R., Voren, G. E., Gumz, M. L., Wingo, C. S. \& Cain, B. D. Dexamethasone stimulates endothelin-1 gene expression in renal collecting duct cells. Steroids $\mathbf{7 7}$, 360-366 (2012).

31. Itani, O. A., Liu, K. Z., Cornish, K. L., Campbell, J. R. \& Thomas, C. P. Glucocorticoids stimulate human sgk1 gene expression by activation of a GRE in its 5 '-flanking region. Am. J. Physiol. Endocrinol. Metab. 283, E971-979 (2002).

32. Hines, E. R., Collins, J. F., Jones, M. D., Serey, S. H. \& Ghishan, F. K. Glucocorticoid regulation of the murine PHEX gene. Am. J. Physiol. Ren. Physiol. 283, F356-363 (2002).
33. Keller-Wood, M., von Reitzenstein, M. \& McCartney, J. Is the fetal lung a mineralocorticoid receptor target organ? Induction of cortisol-regulated genes in the ovine fetal lung, kidney and small intestine. Neonatology 95, 47-60 (2009).

34. Menendez-Castro, C., Nitz, D., Cordasic, N., Jordan, J., Bäuerle, T. \& Fahlbusch, F. B. et al. Neonatal nephron loss during active nephrogenesis-detrimental impact with long-term renal consequences. Sci. Rep. 8, 4542 (2018).

35. Seckl, J. R. Prenatal glucocorticoids and long-term programming. Eur. J. Endocrinol. 151, U49-62 (2004).

36. Zhang, J., Massmann, G. A., Rose, J. C. \& Figueroa, J. P. Differential effects of clinical doses of antenatal betamethasone on nephron endowment and glomerular filtration rate in adult sheep. Reprod. Sci. 17, 186-195 (2010).

37. Moritz, K. M., De Matteo, R., Dodic, M., Jefferies, A. J., Arena, D. \& Wintour, E. M. et al. Prenatal glucocorticoid exposure in the sheep alters renal development in utero: implications for adult renal function and blood pressure control. Am. J. Physiol. Regul. Integr. Comp. Physiol. 301, R500-509 (2011).

38. Wintour, E. M., Moritz, K. M., Johnson, K., Ricardo, S., Samuel, C. S. \& Dodic, M. et al. Reduced nephron number in adult sheep, hypertensive as a result of prenatal glucocorticoid treatment. J. Physiol. 549, 929-935 (2003).

39. Singh, R. R., Cullen-McEwen, L. A., Kett, M. M., Boon, W. M., Dowling, J. \& Bertram, J. F. et al. Prenatal corticosterone exposure results in altered AT1/AT2, nephron deficit and hypertension in the rat offspring. J. Physiol. 579, 503-513 (2007).

\section{ACKNOWLEDGEMENTS}

This study was internally funded by Department of Pediatrics, MetroHealth Medical Center, Case Western Reserve University, Cleveland, $\mathrm{OH}$.

\section{AUTHOR CONTRIBUTIONS}

C.M. and H.K. were responsible for conducting study, data collection, data analysis and writing initial draft of manuscript. M.P., N.K., R.R., P.P., and C.M. were responsible for data analysis and preparing tables and figures and helped write the initial draft of the manuscript. P.S. was responsible for study design, data analysis, data interpretation and wrote the final version of the manuscript. All authors approved the final revised version of submitted manuscript.

\section{COMPETING INTERESTS}

The authors declare no competing interests.

\section{ETHICS APPROVAL}

This retrospective chart review study involving human subjects was in accordance with the ethical standards of the institutional and national research committee and with the 1964 Helsinki Declaration and its later amendments or comparable ethical standards. The Human Investigation Review Committee (IRB) of MetroHealth Medical Center approved this study \# IRB19-00229.

\section{CONSENT STATEMENT}

This was a retrospective study and IRB granted waiver of consent from subjects.

\section{ADDITIONAL INFORMATION}

Correspondence and requests for materials should be addressed to P.S.

Reprints and permission information is available at http://www.nature.com/ reprints

Publisher's note Springer Nature remains neutral with regard to jurisdictional claims in published maps and institutional affiliations. 